\title{
Gemcitabine treatment enhances HER2 expression in low HER2-expressing breast cancer cells and enhances the antitumor effects of trastuzumab emtansine
}

\author{
SHIN KAN ${ }^{1}$, SHIGEO KOIDO ${ }^{1,2}$, MASATO OKAMOTO ${ }^{4}$, KAZUMI HAYASHI ${ }^{1,3}$, MASAKI ITO ${ }^{1}$, YUKO KAMATA $^{1}$, \\ HIDEO KOMITA $^{5}$, TAKEFUMI ISHIDAO ${ }^{6}$, EIJIRO NAGASAKI ${ }^{1,3}$ and SADAMU HOMMA $^{1}$ \\ ${ }^{1}$ Division of Oncology, Research Center for Medical Sciences; ${ }^{2}$ Division of Gastroenterology and Hepatology, \\ Department of Internal Medicine; ${ }^{3}$ Division of Oncology and Hematology, Department of Internal Medicine, Jikei University \\ School of Medicine; ${ }^{4}$ Department of Advanced Immunotherapeutics, Kitasato University School of Pharmacy; \\ ${ }^{5}$ Shimbashi Medical Checkup Office, Jikei University Hospital; ${ }^{6}$ Tella, Inc., Tokyo, Japan
}

Received February 26, 2015; Accepted March 30, 2015

DOI: $10.3892 /$ or.2015.3974

\begin{abstract}
Trastuzumab emtansine (T-DM1), trastuzumabconjugated with a cytotoxic agent, has shown promising antitumor effects in breast cancer. Since a good therapeutic response using T-DM1 treatment requires high human epidermal growth factor receptor 2 (HER2) expression, breast cancers with low or no HER2 expression have not been used for T-DM1 treatment. The aim of the present study was to show that treatment of low HER2-expressing breast cancer cells with gemcitabine (GEM) enhanced HER2 expression using RT-qPCR, immunoblot and flow cytometric analysis. The results showed that GEM treatment significantly enhanced HER2 expression in MDA-MB-231, MCF7 and BT-20 breast cancer cells, while paclitaxel (PTX) treatment induced lower or no enhancement in HER2 expression. The expression of HER2 mRNA was also enhanced in GEM-treated MCF7 cells. Treatment with an inhibitor for nuclear factor-(NF)- $\kappa B$ suppressed GEM-induced HER2 upregulation, indicating that NF- $\kappa \mathrm{B}$ activation by GEM may be associated with HER2 upregulation. T-DM1 binding to HER2 on MCF-7 cells was enhanced by GEM pretreatment and the combined treatment of GEM and T-DM1 synergistically inhibited the proliferation of MCF7 cells. Thus, the combined treatment with GEM and T-DM1 may be a promising therapeutic modality for low HER2-expressing breast cancers, which was facilitated by the unique HER2-upregulating effect of GEM.
\end{abstract}

Correspondence to: Professor Sadamu Homma, Division of Oncology, Research Center for Medical Sciences, Jikei University School of Medicine, 3-25-8 Nishi-shimbashi, Minato-ku, Tokyo 105-8461, Japan

E-mail: sahya@jikei.ac.jp

Key words: human epidermal growth factor receptor 2, gemcitabine, paclitaxel, trastuzumab emtansine, combination therapy

\section{Introduction}

An estimated 1.7 million individuals are diagnosed with breast cancer and $>450,000$ individuals succumb to the disease each year worldwide (1). Breast cancer ranks sixth with regard to mortality among women in Japan (2). Accordingly, establishment of novel modalities for treatment against breast cancer is urgently needed.

Human epidermal growth factor receptor 2 (HER2) is a 185-kDa transmembrane tyrosine kinase receptor and its signaling promotes cell proliferation, differentiation and survival through the RAS-RAF-MAPK and PI3K-Akt pathways $(3,4)$. HER2 overexpression at the gene or protein level is observed in 20-25\% of human breast cancers, and its overexpression is associated with a poor clinical outcome (5). Trastuzumab, a monoclonal antibody specific to the extracellular domain of HER2, is a promising tool for treating breast cancers with HER2 overexpression (6). In a phase III clinical trial, the combined treatment of trastuzumab and paclitaxel (PTX) for metastatic HER2-positive breast cancer elicited improved response, progression-free survival and overall survival compared with chemotherapy without trastuzumab (6,7). The mechanism underlying the antitumor effects of trastuzumab includes the inhibition of HER2 downstream signaling pathways and activation of the antibody-dependent cell-mediated cytotoxicity (ADCC) response (8-10). However, the majority of patients who have an initial response to trastuzumab acquire resistance to the drug during prolonged treatment $(6,7,9)$.

Recently, trastuzumab emtansine (T-DM1), a conjugate of trastuzumab and derivative of maytansine 1 (DM1) was developed as a new drug for anti-HER2-targeting therapy. T-DM1 binds to cell-surface HER 2 receptors and is delivered into lysosomes via endocytosis where it is digested by lysosomal enzymes. The active form of DM1 is released into the cytoplasm and inhibits the assembly of microtubules (11-13). The cytotoxic activity of T-DM1 towards breast and gastric cancer cells was stronger than that of trastuzumab in vitro and in vivo even if the tumor cells were resistant to trastuzumab by 
PIK3CA mutation $(11,14,15)$. In phase III clinical studies, the efficacy of T-DM1 was found to be superior to that of lapatinib and docetaxel in patients with HER2-positive advanced breast cancers resistant to trastuzumab and taxanes (16).

Trastuzumab or T-DM1 have been used for the treatment of breast cancers with HER 2 overexpression. To determine indications for trastuzumab or T-DM1 therapy, the extent of HER2 expression in breast cancer cells was evaluated by immunohistochemistry (IHC) and gene amplification was determined by fluorescence in situ hybridization (FISH) $(7,17,18)$. Breast cancers with a high HER2 expression or FISH positivity are associated with a good response to trastuzumab or T-DM1 $(7,11,16,18,19)$. Thus, innovative modalities that enable breast cancer patients with a low HER2 expression to receive trastuzumab or T-DM1 therapy are required.

Combined treatment with gemcitabine (GEM) and PTX produces longer progression-free survival and improved response rates than PTX alone in metastatic breast cancer patients who failed anthracycline-based chemotherapy $(20,21)$. GEM is a nucleoside analog that arrests cells in the S-phase in the cell cycle and it is widely used as a standard therapeutic agent for pancreatic cancer and metastatic breast cancer. By contrast, PTX is an inhibitor of microtubule de-polymerization that induces cell-cycle arrest in the G2-M phase. The improved therapeutic efficacy of the combined therapy with GEM and PTX against breast cancer appears to be based on their different cytotoxic mechanisms. As most breast cancer patients express HER2 at low or moderate levels, they have been treated with hormone therapy or chemotherapy. If a low HER2 expression level in breast cancer was to be enhanced by treatment with a considerable agent, the T-DM1 treatment could be applied by combination with that agent. We have previously reported that GEM treatment induced the upregulation of Wilms tumor 1 (WT1) in pancreatic cancer cells and enhanced the efficacy of WT1-targeting immunotherapy against pancreatic cancer (22). In the present study, we aimed to demonstrate that treatment of low HER2-expressing breast cancer cells with GEM enhanced their HER 2 expression in vitro. The antitumor effects of the combined treatment with GEM and T-DM1 for low HER2expressing breast cancer cells was investigated.

\section{Materials and methods}

Cell lines and agents. MDA-MB-231 human breast cancer cells used in our laboratory were confirmed to be original MDA-MB-231 by DNA short tandem repeat analysis. MCF7 cells were obtained from RIKEN BRC through the National Bio-Resource Project of the MEXT (Ibaraki, Japan). The BT-20 cells were provided from Dr Shigeo Koido, from Jikei University. GEM was purchased from Eli Lilly Japan (Kobe, Japan). 5-Fluorouracil (5-FU) was purchased from Kyowa Hakko Kirin Co. (Tokyo, Japan) and PTX was obtained from Sigma-Aldrich (St. Louis, MO, USA). The NF- $\kappa$ B inhibitor BAY11-7082 was purchased from Wako Pure Chemical Industries, Ltd. (Osaka, Japan). Trastuzumab was a gift from Chugai, Inc. (Tokyo, Japan) and T-DM1 was provided by Genentech, Inc. (South San Francisco, CA, USA).

FACS analysis. To assess the HER 2 expression level, the cells were incubated with phycoerythrin (PE)-labeled anti-human
HER2 (24D2) or corresponding isotype control antibodies (BioLegend, San Diego, CA, USA) in FACS buffer for $30 \mathrm{~min}$ at $4^{\circ} \mathrm{C}$. After being washed, the cells were analyzed using a MACSQuant Analyzer (Miltenyi Biotech K.K., Bergisch Gladbach, Germany). To assess the T-DM1 binding level of the MCF7 cells, $1 \times 10^{6}$ cells were incubated with $10 \mu \mathrm{g} / \mathrm{ml}$ T-DM1 at $37^{\circ} \mathrm{C}$ for $1 \mathrm{~h}$. After being washed, the cells were incubated with PE-labeled anti-human IgG (HP6017) or corresponding isotype control antibodies (both from BioLegend) in FACS buffer for $30 \mathrm{~min}$ at $4^{\circ} \mathrm{C}$. The cells were analyzed using a MACSQuant Analyzer (Miltenyi Biotech K.K.). Prior to using the analyzer, $4 \mu \mathrm{g} / \mathrm{ml}$ propidium iodide (PI) (Sigma-Aldrich) was added to the sample to exclude dead cells. The mean fluorescence intensity (MFI) of HER2 and human $\operatorname{IgG}$ was analyzed using MACSQuantify software.

Reverse transcription-quantitative polymerase chain reaction $(R T-q P C R)$. Total RNA was extracted from the cells using TRIzol reagent (Life Technologies, Carlsbad, CA, USA) followed by phenol-chloroform extraction and isopropanol precipitation or the Micro-to-Midi Total RNA Purification System (Life Technologies). cDNA was synthesized from $500 \mathrm{ng}$ of the total RNA using the PrimeScript RT reagent kit (Takara Bio, Inc., Otsu, Shiga, Japan) and the GeneAmp PCR System 9700 (Applied Biosystems). For RT-qPCR detection of HER 2 and 18S rRNA, $5 \mathrm{ng}$ of cDNA was amplified using SYBR Premix Ex Taq II (Takara Bio, Inc.) and the 7300 Real-Time PCR System (Applied Biosystems). The PCR conditions consisted of an initial denaturation step $\left(95^{\circ} \mathrm{C}\right.$ for $\left.30 \mathrm{sec}\right)$ followed by 40 cycles $\left(95^{\circ} \mathrm{C}\right.$ for $5 \mathrm{sec}$ and $62^{\circ} \mathrm{C}$ for $\left.31 \mathrm{sec}\right)$ and a dissociation step. The primer sequences (Operon Biotechnologies K.K., Tokyo, Japan) used were: HER2 5'-TCCTGTGTGGAC CTGGAT-3' (forward), and 5'-TGCCGTCGCTTGATGAG-3' (reverse); and 18S rRNA 5'-CGGCTACCACATCCAAGGAA-3' (forward), and 5'-GCTGGAATTACCGCGGCT-3' (reverse). The data were analyzed using the comparative $\Delta \Delta \mathrm{Ct}$ method by calculating the difference between the threshold cycle (CT) values of the target and the reference genes for each sample and then comparing the $\Delta \mathrm{CT}$ values of each drug treatment to the untreated group.

Immunoblot analysis. The cells were homogenized in RIPA buffer (20 mM Tris-HCl pH 7.5, $150 \mathrm{mM} \mathrm{NaCl}, 0.1 \%$ deoxycholic acid, 1 mM EDTA, 0.1\% SDS, $1 \%$ NP-40) with $100 \mathrm{mM}$ PMSF, $1 \mathrm{mg} / \mathrm{ml}$ leupeptin, $1 \mathrm{mg} / \mathrm{ml}$ aprotinin and $0.9 \mathrm{M}$ $\mathrm{Na}_{3} \mathrm{VO}_{4}$, and the protein concentrations were analyzed using the Pierce BCA protein assay kit (Thermo Fisher Scientific, Inc., Waltham, MA, USA). Protein samples $(10 \mu \mathrm{g})$ were separated by electrophoresis in $7.5 \%$ sodium dodecyl sulfatepolyacrylamide gels (ATTO, Tokyo, Japan) and transferred to polyvinylidene difluoride membranes (Bio-Rad Laboratories, Hercules, CA, USA). After being blocked with $3 \%$ non-fat milk and 3\% bovine serum albumin for $1 \mathrm{~h}$, the membrane was treated with Abs directed against HER2 (1:1,000) (e2-4001 + 3B5; Thermo Fisher Scientific, Inc.) and GAPDH $(1: 600,000)(2 \mathrm{D} 4 \mathrm{~A} 7$; Abcam Inc., Cambridge, UK) and then with secondary antibodies (Cell Signaling Technology Inc., Danvers, MA, USA) conjugated to horseradish peroxidase. Chemi-Lumi One Super (Nakalai Tesque, Inc., Kyoto, Japan) was used for chemiluminescence detection. 
A
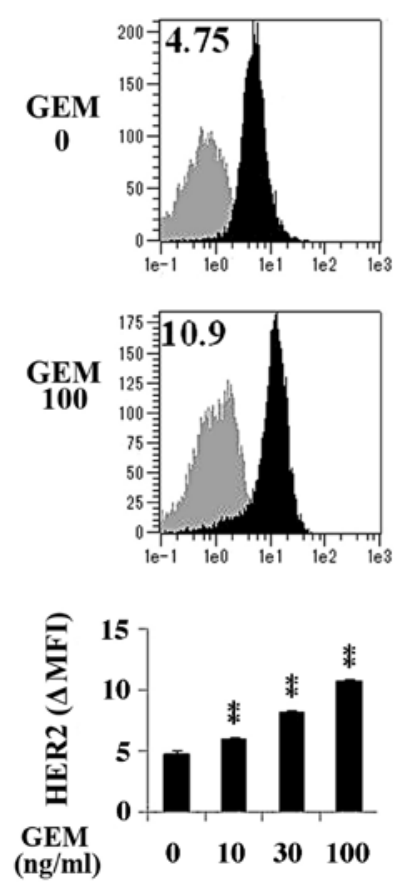

B
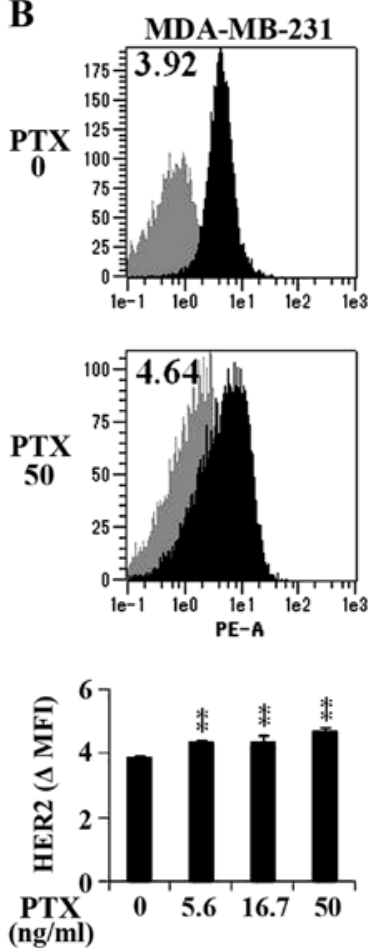

MCF7
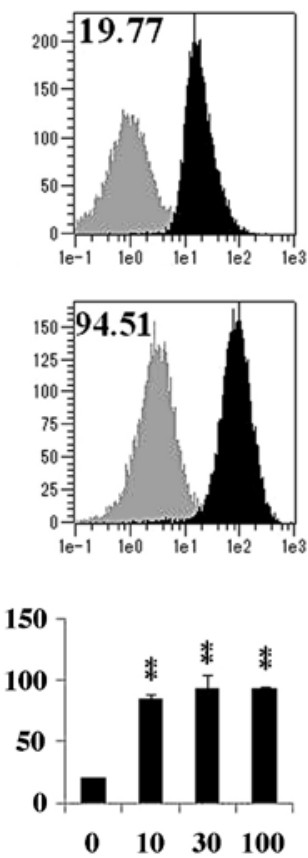

MCF7
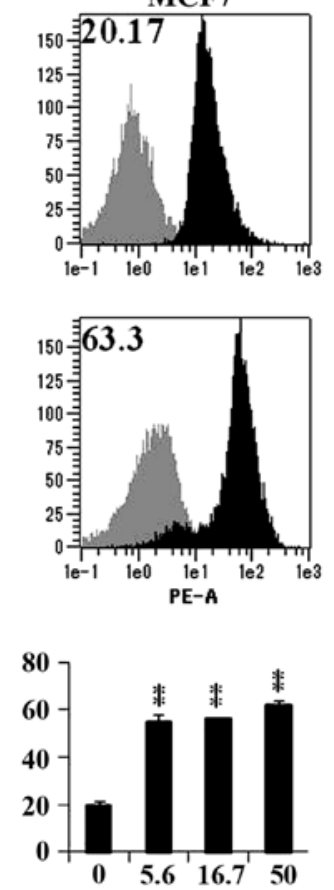

BT-20
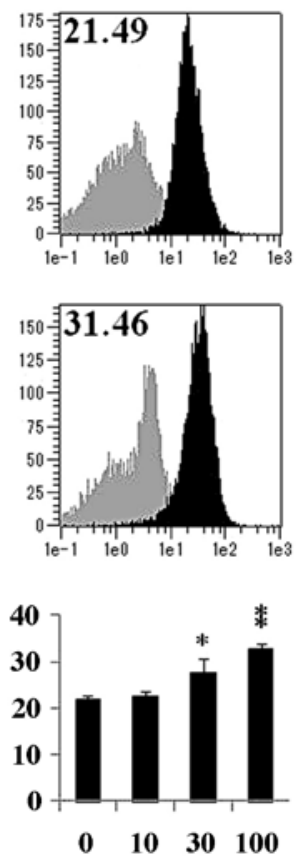
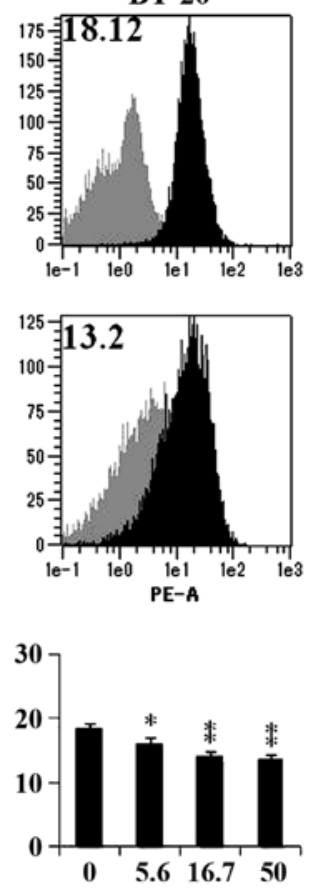

Figure 1. GEM and PTX induce HER2 upregulation in three human breast cancer cell lines. (A) The cells were untreated (upper panel) or treated (middle panel) with GEM (100 ng/ml) for $2 \mathrm{~h}$. After being washed with PBS, the cells were incubated for $48 \mathrm{~h}$. HER 2 expression was examined by flow cytometry. The gray and black histogram profiles indicate the isotype control and HER 2 expression, respectively. Alterations in the HER 2 expression (mean \pm SD, $=3$ ) are shown in graphs (lower panel). The values indicate the $\Delta$ MFI of HER2, such as the MFI of HER2 minus that of the isotype control of the samples. $\mathrm{P}<0.05$ and ${ }^{* *} \mathrm{P}<0.01$ vs. the untreated samples. (B) The cells were untreated (upper panel) or treated (middle panel) with PTX (50 ng/ml) for $24 \mathrm{~h}$. The experimental procedures were the same as in (A). Alterations in HER2 expression (mean $\pm \mathrm{SD}, \mathrm{n}=3$ ) are shown in the graphs (lower panel). The values indicate the $\Delta \mathrm{MFI}$ of HER2, such as the MFI of HER2 minus that of the isotype controls of the samples. ${ }^{*} \mathrm{P}<0.05$ and ${ }^{* *} \mathrm{P}<0.01$ vs. the untreated samples. GEM, gemcitabine; PTX, paclitaxel; HER2, human epidermal growth factor receptor 2; PBS, phosphate-buffered saline; PE, phycoerythrin; MFI, mean fluorescence intensity.

Estimation of the antiproliferative effects of different agents by in vitro cell growth assays. MCF7 cells in the culture dishes were treated with GEM $(0,10$ and $30 \mathrm{ng} / \mathrm{ml})$ for $2 \mathrm{~h}$, PTX $(0$, 5.6 and $16.7 \mathrm{ng} / \mathrm{ml})$ for $24 \mathrm{~h}$ or $5-\mathrm{FU}(0,10$ or $40 \mu \mathrm{g} / \mathrm{ml})$ for
1.5 h. After washing the cells with phosphate-buffered saline (PBS), they were incubated in a medium containing T-DM1 $(0,10$ and $30 \mu \mathrm{g} / \mathrm{ml})$ for $96 \mathrm{~h}$. Identical numbers of trypan blue non-stained cells were seeded in 96 -well plates $\left(3 \times 10^{3} /\right.$ well). 
A

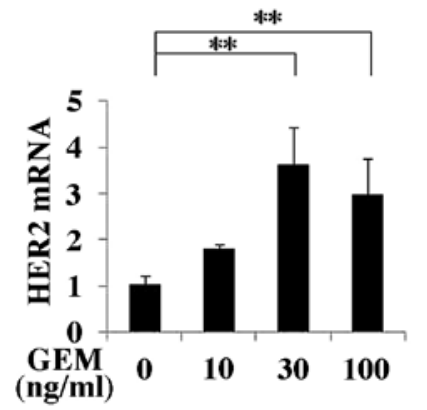

B

HER2

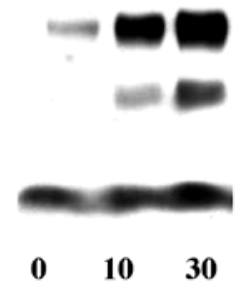

C

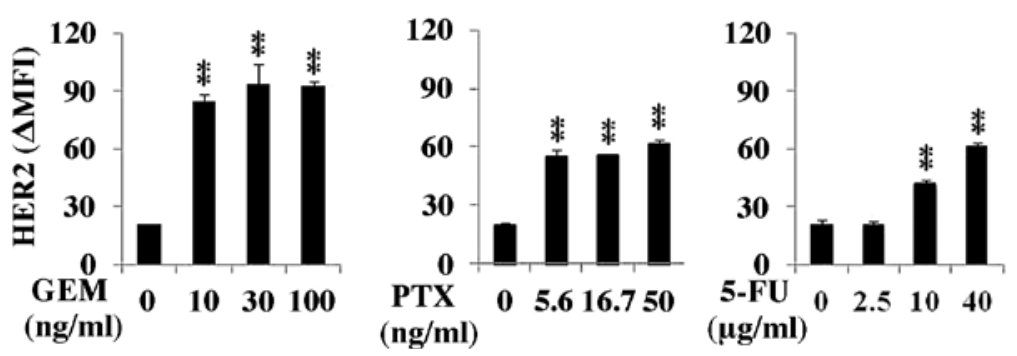

Figure 2. GEM treatment enhanced HER2 expression of the MCF7 cells at the mRNA and protein levels. (A) MCF7 cells were treated with GEM $(0,10,30$ or $100 \mathrm{ng} / \mathrm{ml}$ ) for $2 \mathrm{~h}$, washed with PBS and incubated for another $48 \mathrm{~h}$ in fresh medium. The HER2 mRNA expression in the cells was analyzed using RT-qPCR $(\mathrm{n}=3)$. (B) The MCF7 cells were treated with GEM $(0,10,30$ or $100 \mathrm{ng} / \mathrm{ml})$ for $2 \mathrm{~h}$, washed with PBS and incubated for another $48 \mathrm{~h}$ in fresh medium. HER2 and GAPDH protein expression was examined by immunoblot analysis. (C) MCF7 cells were treated with GEM for $2 \mathrm{~h}, \mathrm{PTX}$ for $24 \mathrm{~h}$ or 5 -FU for $1.5 \mathrm{~h}$, washed with PBS and cultured for $48 \mathrm{~h}$ in fresh medium. The HER2 expression was analyzed by flow cytometry. The values indicate the $\triangle$ MFI of HER2, such as the MFI of HER2 minus that of the isotype control of the samples $(n=3)$. ${ }^{*} \mathrm{P}<0.05$ and ${ }^{* *} \mathrm{P}<0.01$ vs. the untreated samples. GEM, gemcitabine; HER2, human epidermal growth factor receptor 2; PBS, phosphate-buffered saline; MFI, mean fluorescence intensity.

After a 96-h incubation, cell growth was examined by spectrophotometry using Cell Counting Kit-8 (Dojindo Molecular Technologies, Inc., Kumamoto, Japan). Fluorescence was measured at $450 \mathrm{~nm}$ using an iMark microplate absorbance reader (Bio-Rad Laboratories).

Statistical analysis. Data are presented as the mean \pm standard deviation (SD). Comparisons between the untreated control and drug-treated groups were performed by the unpaired Student's or Welch's t-tests for two independent groups and the Dunnett or Bonferroni-Dunn methods for multiple-group comparisons. $\mathrm{P}<0.05$ was considered to indicate a statistically significant result. Statistical analyses were performed using Microsoft Office Excel 2007 (Microsoft Corporation, Redmond, WA, USA) with the add-in software Statcel 3 (OMS Publishing Inc., Saitama, Japan).

\section{Results}

GEM treatment increases HER2 expression in breast cancer cells with low HER2 expression. MCF7, MDA-MB-231 and BT-20 human breast cancer cells have low HER2 expression levels. Alterations in HER2 expression in these cell lines by treatment with GEM or PTX was examined. HER2-expression was significantly enhanced by GEM treatment, although the extent of HER2 upregulation was different among the three cell lines (Fig. 1A). PTX treatment induced a low and moderate HER2 upregulation in the MDA-MB-231 and MCF7 cells, respectively, whereas HER2 was downregulated in BT-20 cells (Fig. 1B). HER2 mRNA in GEM-treated MCF7 cells significantly increased when the cells were treated with 30 or $100 \mathrm{ng} / \mathrm{ml}$ GEM (Fig. 2A). The results from the immunoblot analysis showed that HER 2 protein expression in GEM-treated MCF7 cells increased (Fig. 2B). Although HER2 expression in PTX (50 ng/ml)- or 5-FU (40 $\mu \mathrm{g} / \mathrm{ml})$-treated MCF7 cells increased 3.2- or 3-fold, respectively, a larger increase, i.e., 4.6-fold, was identified with GEM $(100 \mathrm{ng} / \mathrm{ml})$ treatment (Fig. 2C).

GEM-mediated HER2 upregulation is inhibited by treatment with an $N F-\kappa B$ inhibitor. The upregulation of HER 2 mRNA induced by GEM treatment was significantly inhibited by treatment with the NF- $\kappa$ B inhibitor BAY11-7082 (Fig. 3A and B). Fig. 3A shows the result obtained by prolonged treatment of BAY11-7082 with 2 h GEM treatment. Fig. 3B shows the result obtained by $2 \mathrm{~h}$ simultaneous treatment of GEM and BAY11-7082. The increase of the HER2 protein expression on the cell surface induced by GEM treatment was mildly suppressed by prolonged treatment with $6 \mu \mathrm{M}$ BAY117082 (Fig. 3C).

T-DM1 binding to HER2 on MCF7 cells is increased by GEM treatment. As HER2 expression was upregulated on GEM-treated breast cancer cells, we examined whether T-DM1 binding to HER2 increases on GEM-treated MCF7 cells. T-DM1 binding to HER2 on the MCF7 cells was increased following HER2 upregulation by GEM treatment (Fig. 4A and B). As shown in Fig. 4A, HER2 expression was increased 3.95-fold and T-DM1 binding was increased 3.62-fold by GEM treatment (Fig. 4A), indicating that the extent of the increase in HER 2 expression and T-DM1 binding was similar. T-DM1 binding to HER2 on MCF7 cells treated with GEM $(10 \mathrm{ng} / \mathrm{ml})$ increased at 3.56-fold compared with the untreated MCF7 cells (Fig. 4B). 


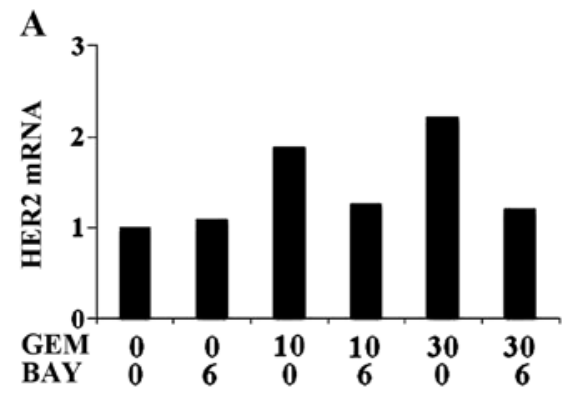

C
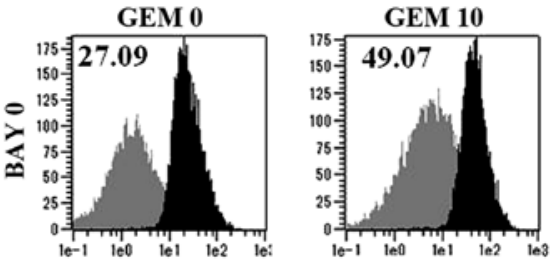

B
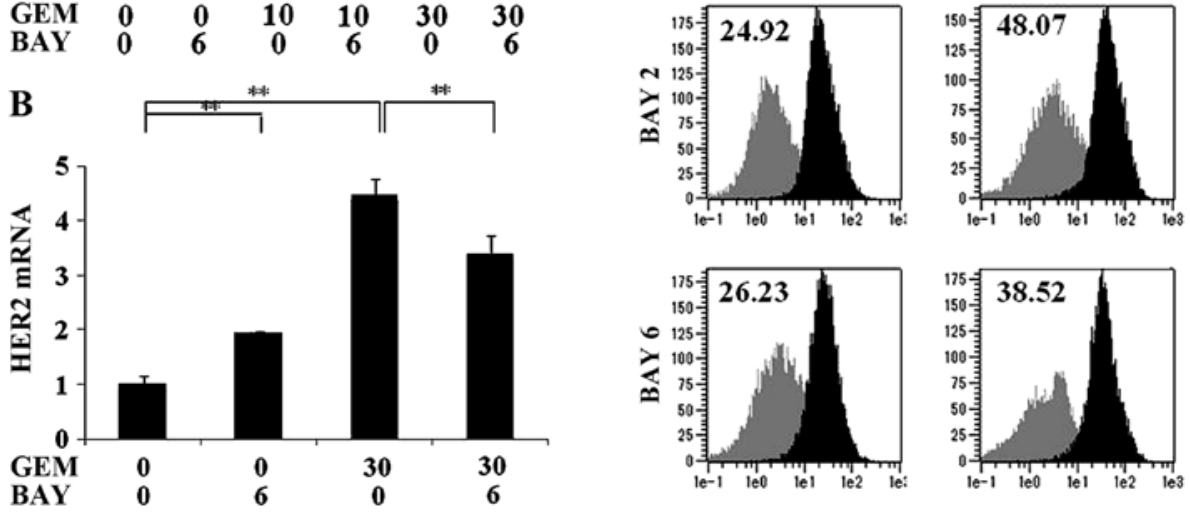

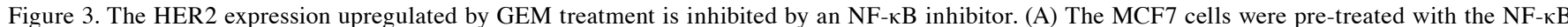
inhibitor BAY11-7082 (BAY) $(0$ and $6 \mu \mathrm{M})$ for $4 \mathrm{~h}$ and then GEM $(0,10$ and $30 \mathrm{ng} / \mathrm{ml})$ was added for $2 \mathrm{~h}$ in the presence of BAY. The cells were washed with PBS and incubated in fresh medium with BAY $(0$ and $6 \mu \mathrm{M})$ for $24 \mathrm{~h}$. The cells were collected and analyzed for the HER2 expression using qRT-PCR (n=2) (B) MCF7 cells were simultaneously treated with GEM $(0$ and $30 \mathrm{ng} / \mathrm{ml})$ and BAY $(0$ and $6 \mu \mathrm{M})$ for $2 \mathrm{~h}$, washed with PBS and incubated in fresh medium for another $48 \mathrm{~h}$. The cells were collected and analyzed for HER2 mRNA expression using RT-qPCR ( $\mathrm{n}=3)$. ${ }^{* *} \mathrm{P}<0.01$. (C) MCF7 cells were pre-treated with the NF- $\mathrm{kB}$ inhibitor BAY11-7082 (BAY) $(0,2$ and $6 \mu \mathrm{M})$ for $4 \mathrm{~h}$ and then GEM $(0$ and $10 \mathrm{ng} / \mathrm{ml})$ was added for $2 \mathrm{~h}$ in the presence of BAY. The cells were washed with PBS and incubated in fresh medium with BAY $(0,2$ and $6 \mu \mathrm{M})$ for $24 \mathrm{~h}$. The cells were collected and examined for HER 2 expression using flow cytometry $(\mathrm{n}=2)$. The values indicate the $\Delta$ MFI of HER2, such as the MFI of HER2 minus that of the isotype control of the samples. HER2, human epidermal growth factor receptor 2; GEM, gemcitabine; PBS, phosphate-buffered saline; MFI, mean fluorescence intensity.

A
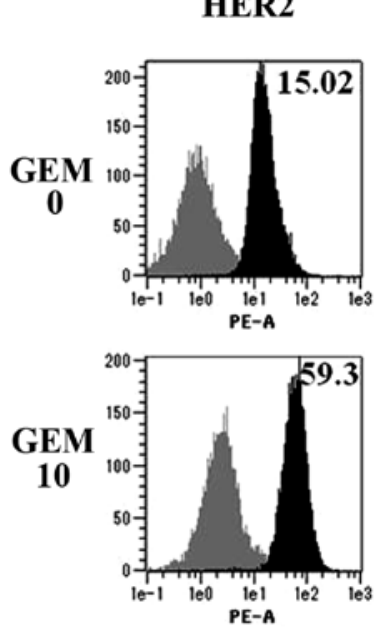

T-DM1 binding
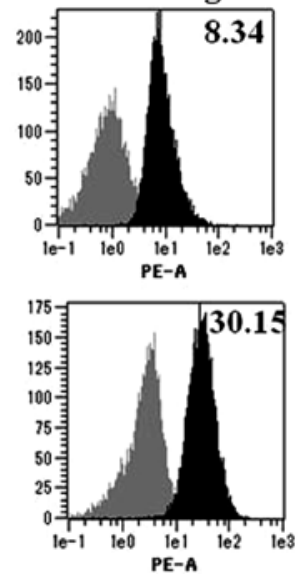

B
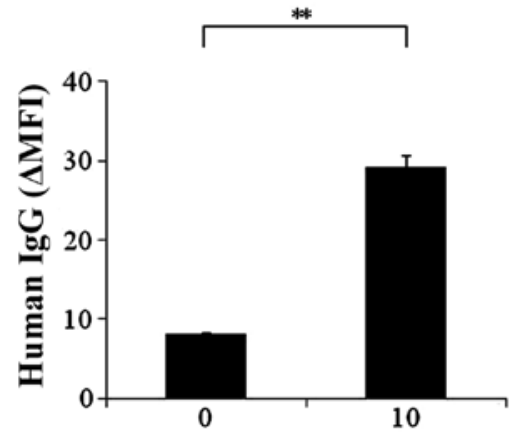

Figure 4. T-DM1 binding to the MCF7 cells is increased by GEM treatment. (A) MCF7 cells were untreated or treated with GEM (10 ng/ml) for $2 \mathrm{~h}$, washed with PBS and incubated in fresh medium for $48 \mathrm{~h}$. HER2 expression of the cells was examined by flow cytometry. Additionally, untreated or GEM-treated cells were detached and treated with T-DM1 $(10 \mu \mathrm{g} / \mathrm{ml})$ for $1 \mathrm{~h}$. The cells were analyzed for T-DM1 binding by flow cytometry using PE-labeled anti-human IgG. Upper left panel, HER2 expression of untreated MCF7 cells. Upper right panel, T-DM1 binding to untreated MCF7 cells. Lower left panel, HER2 expression on GEM-treated MCF7 cells. Lower right panel, T-DM1 binding to GEM-treated MCF7 cells. Grey and black areas indicate the isotype control and specific antibody, respectively. Values indicate $\Delta$ MFI for HER2, such as the MFI for HER2 minus that of the isotype control for the samples. (B) As described in (A), the untreated and GEM-treated MCF7 cells were incubated with T-DM1 for $1 \mathrm{~h}$, and the binding of T-DM1 was examined by flow cytometry using PE-labeled anti-human IgG. The $\Delta$ MFI of human IgG was calculated as the MFI of PE-labeled anti-human IgG minus that of the isotype control of the samples (n=3), ${ }^{* *} \mathrm{P}<0.01$. T-DM1, trastuzumab emtansine; GEM, gemcitabine; PBS, phosphate-buffered saline; MFI, mean fluorescence intensity.

Combined treatment with GEM and T-DMI synergistically inhibits MCF7 cell proliferation. When the MCF7 cells were pre-treated with $10 \mathrm{ng} / \mathrm{ml} \mathrm{GEM}, 10 \mu \mathrm{g} / \mathrm{ml}$ T-DM1 treatment produced marked synergistic antiproliferation effects on the MCF7 cells (Fig. 5). No synergistic effects were observed when the MCF7 cells were treated with PTX and T-DM1. Low 


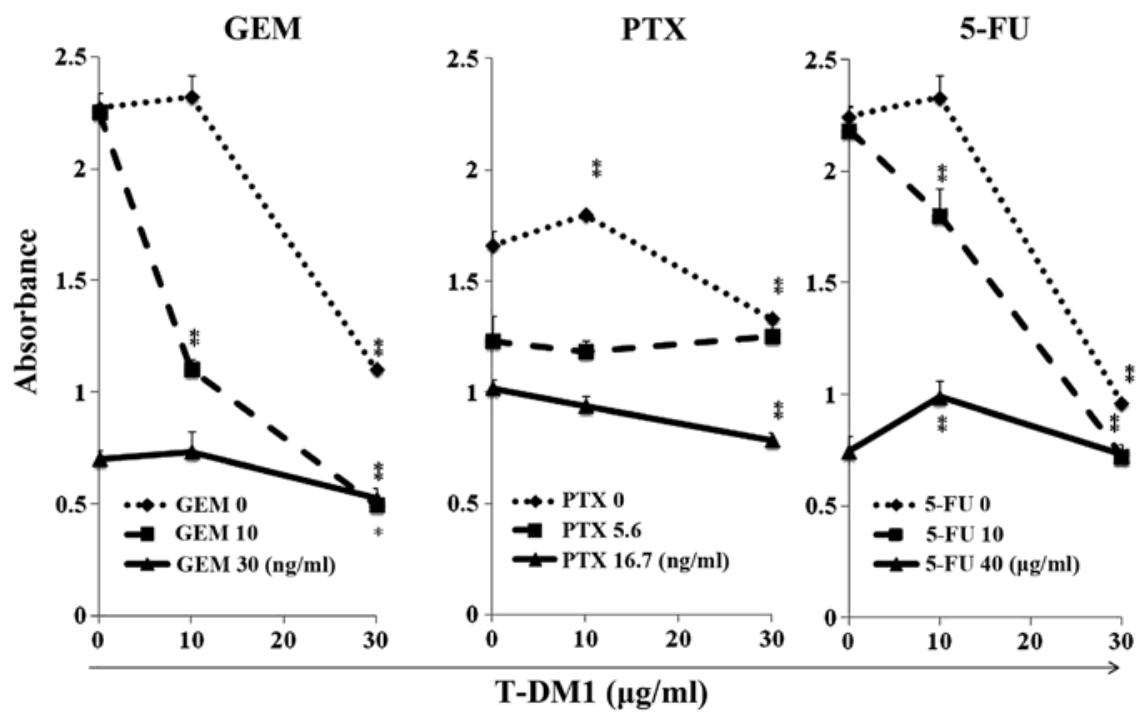

Figure 5. Combined treatment with GEM and T-DM1 synergistically inhibited the growth of MCF7 cells. MCF7 cells were treated with GEM for $2 \mathrm{~h}$, PTX for $24 \mathrm{~h}$ or 5 -FU for $1.5 \mathrm{~h}$. The cells were washed with PBS and incubated in medium containing T-DM1 $(0,10 \mathrm{or} 30 \mu \mathrm{g} / \mathrm{ml})$ for $96 \mathrm{~h}$. The cells were detached and an identical number of trypan-blue non-stained cells was seeded into the 96 -well plates $\left(3 \times 10^{3}\right.$ cells/well) and incubated for $96 \mathrm{~h}$. Cell growth was examined by spectrophotometry. Vertical axis, OD; horizontal axis, concentration of T-DM1 $(\mu \mathrm{g} / \mathrm{ml})$. ${ }^{*} \mathrm{P}<0.05$ and ${ }^{* *} \mathrm{P}<0.01$ vs. the untreated samples with T-DM1 at each GEM, PTX or 5-FU concentration. GEM, gemcitabine; T-DM1, trastuzumab emtansine; PTX, paclitaxel; 5-FU, 5-fluorouracil; PBS, phosphate-buffered saline.

synergism was observed following the combined treatment with 5-FU $(10 \mu \mathrm{g} / \mathrm{ml})$ and T-DM1 $(10 \mu \mathrm{g} / \mathrm{ml})$.

\section{Discussion}

In the present study, we found that treatment with GEM or PTX enhanced the HER2 expression of breast cancer cells with a low HER2 expression. GEM had stronger potency for HER2 upregulation than PTX, suggesting that modulation of the DNA synthesis may be more associated with HER2 upregulation. An increase of HER 2 expression by GEM was induced at the transcriptional level and it appears to be at least partially regulated by NF- $\mathrm{B}$ signaling. HernándezVargas et al reported that the NF-кB pathway was activated in GEM-treated breast cancer cells to induce GEM resistance (23). NF- $\kappa B$ has been reported to play a critical role in HER2 overexpression in breast cancer (24). Cao et al reported that long-term radiation treatment for breast cancer activated $\mathrm{NF}-\kappa \mathrm{B}$, resulting in accelerated NF- $\mathrm{BB}$ signaling to the HER2 promoter for HER 2 mRNA transactivation (25). It has been reported that GEM has a stronger NF- $\mathrm{KB}$ activating ability than PTX or 5-FU (23). Together, a higher HER2 upregulation in breast cancer cells by GEM treatment may be the result of higher NF- $\kappa \mathrm{B}$ activation than PTX treatment.

T-DM1 is a conjugate of trastuzumab and the cytotoxic agent emtansine $(12,13)$. In addition to the cytotoxic activity of DM1, T-DM1 has two other antitumor activities including functioning as a monoclonal antibody that blocks intracellular signal transduction and ADCC. The formation of HER2 homodimers or HER 2 and HER1/3/4 heterodimers on tumor cells accelerates the phosphorylation process of RAS/ RAF/MEK/MARK and PI3K/AKT/mTOR without ligand binding, resulting in the promotion of tumorigenesis (26). It has been shown that trastuzumab inhibits the PI3K/ AKT/mTOR pathway mediated by PTEN (27). Mutation of phosphoinositide 3-kinase (PI3K) was found to be closely associated with trastuzumab resistance (28) and $42 \%$ of HER2-enriched breast cancers have a PI3K mutation (29). It may be possible that T-DM1 treatment has less resistance to breast cancers with PI3K mutation than trastuzumab, and an increase in HER2 expression and the resultant increase in T-DM1 binding to breast cancer cells may be beneficial for treating breast cancers with PIK3CA mutations.

Although it is possible that HER2 upregulation by GEM enhances the ADCC activity of T-DM1, we did not observe enhanced trastuzumab or T-DM1-mediated ADCC activity towards GEM-treated breast cancer cells. Since the ${ }^{51} \mathrm{Chromium}$ $\left({ }^{51} \mathrm{Cr}\right)$ release assay was not appropriate for measuring the ADCC activity against GEM-treated target cells due to the large spontaneous release of ${ }^{51} \mathrm{Cr}$, enhanced ADCC activity by GEM treatment was demonstrated by another appropriate modality. Resistance to ADCC has been induced by long-term treatment with trastuzumab, and a possible mechanism involved the downregulation of the extracellular domain of HER2 (30). Notably, lapatinib, a HER2 tyrosine kinase inhibitor, accumulated HER 2 and potentiated trastuzumab-dependent cell cytotoxicity (31). GEM treatment may also recover the HER2 expression of breast cancer cells with HER2 downregulation and overcome resistance to trastuzumab-mediated ADCC.

It was confirmed that the amount of T-DM1 binding to HER 2 on the breast cancer cells was increased along with the HER2 upregulation induced by GEM treatment, and the extent of the increase in HER2 expression and T-DM1 binding was almost identical. These results suggest that T-DM1 successfully bound to HER 2 molecules that were upregulated by GEM treatment. The more T-DM1 that binds to cell surface HER2, the more active DM1 is generated in the cells (11-13).

Significant synergistic antiproliferative effects between GEM and T-DM1 are based on high HER 2 upregulation induced by GEM and result in the enhancement of T-DM1 binding. By contrast, synergistic antiproliferative effects were not observed in PTX and T-DM1-treated MCF7 cells although 
HER2 upregulation was induced by PTX treatment. One possible reason for this result may be that PTX is an inhibitor of microtubule de-polymerization, which is similar to DM1, while GEM is an inhibitor of DNA synthesis. It is conceivable that the combined treatment with chemotherapeutic agents with different mechanisms may be more cytotoxic. Although synergistic antiproliferative effects were observed between 5-FU $(10 \mu \mathrm{g} / \mathrm{ml})$ and T-DM1 $(10 \mu \mathrm{g} / \mathrm{ml})$, synergism was lower than that between GEM and T-DM1, possibly due to a lower HER 2 upregulation by 5-FU compared with GEM.

A considerable number of breast cancer patients have been unable to receive therapeutic benefits by T-DM1 treatment due to low HER2 expression in their breast cancer tissues. Pre-treatment with GEM may overcome this limitation of T-DM1 therapy by inducing HER2 upregulation and enabling a low HER2-expressing breast cancer patients to be candidates for T-DM1 therapy. Experiments involving HER2 upregulation in vivo by GEM treatment are now being performed using immune-deficient mice transplanted with human low HER2-expressing breast cancer cells.

\section{References}

1. Cancer statistics, World Cancer Research Fund International http://www.wcrf.org/cancer_statistics/world_cancer_statistics. php. http://www.wcrf.org/cancer_statistics/cancer_facts/ women-breast-cancer.php. Accessed: date?

2. Center for Cancer Control and Information Services, National Cancer Center, Japan: Vital Statistics Japan. Ministry of Health, Labour and Welfare, 2013.

3. Hudis CA: Trastuzumab - mechanism of action and use in clinical practice. N Engl J Med 357: 39-51, 2007.

4. Yarden Y and Sliwkowski MX: Untangling the ErbB signalling network. Nat Rev Mol Cell Biol 2: 127-137, 2001.

5. Slamon DJ, Clark GM, Wong SG, Levin WJ, Ullrich A and McGuire WL: Human breast cancer: Correlation of relapse and survival with amplification of the HER-2/neu oncogene. Science 235: 177-182, 1987.

6. Slamon DJ, Leyland-Jones B, Shak S, Fuchs H, Paton V, Bajamonde A, Fleming T, Eiermann W, Wolter J, Pegram M, et al: Use of chemotherapy plus a monoclonal antibody against HER 2 for metastatic breast cancer that overexpresses HER 2. N Engl J Med 344: 783-792, 2001.

7. Seidman AD, Fornier MN, Esteva FJ, Tan L, Kaptain S, Bach A, Panageas KS, Arroyo C, Valero V, Currie V, et al: Weekly trastuzumab and paclitaxel therapy for metastatic breast cancer with analysis of efficacy by HER 2 immunophenotype and gene amplification. J Clin Oncol 19: 2587-2595, 2001.

8. Nahta R and Esteva FJ: Herceptin: Mechanisms of action and resistance. Cancer Lett 232: 123-138, 2006.

9. Nahta R, Yu D, Hung MC, Hortobagyi GN and Esteva FJ: Mechanisms of disease: Understanding resistance to HER2 targeted therapy in human breast cancer. Nat Clin Pract Oncol 3: 269-280, 2006.

10. Lewis GD, Figari I, Fendly B, Wong WL, Carter P, Gorman C and Shepard HM: Differential responses of human tumor cell lines to anti-p185HER2 monoclonal antibodies. Cancer Immunol Immunother 37: 255-263, 1993.

11. Burris HA III, Tibbitts J, Holden SN, Sliwkowski MX and Lewis Phillips GD: Trastuzumab emtansine (T-DM1): A novel agent for targeting HER2 ${ }^{+}$breast cancer. Clin Breast Cancer 11: 275-282, 2011.

12. LoRusso PM, Weiss D, Guardino E, Girish S and Sliwkowski MX: Trastuzumab emtansine: A unique antibody-drug conjugate in development for human epidermal growth factor receptor 2-positive cancer. Clin Cancer Res 17: 6437-6447, 2011.

13. Barok M, Joensuu $\mathrm{H}$ and Isola J: Trastuzumab emtansine: Mechanisms of action and drug resistance. Breast Cancer Res 16: 209, 2014.

14. Barok M, Tanner M, Köninki K and Isola J: Trastuzumab-DM1 causes tumour growth inhibition by mitotic catastrophe in trastuzumab-resistant breast cancer cells in vivo. Breast Cancer Res 13: R46, 2011.
15. Barok M, Tanner M, Köninki K and Isola J: Trastuzumab-DM1 is highly effective in preclinical models of HER2-positive gastric cancer. Cancer Lett 306: 171-179, 2011.

16. Verma S, Miles D, Gianni L, Krop IE, Welslau M, Baselga J, Pegram M, Oh DY, Diéras V, Guardino E, et al; EMILIA Study Group: Trastuzumab emtansine for HER2-positive advanced breast cancer. N Engl J Med 367: 1783-1791, 2012.

17. Cox G, Vyberg M, Melgaard B, Askaa J, Oster A and O'Byrne KJ: Herceptest: HER2 expression and gene amplification in non-small cell lung cancer. Int J Cancer 92: 480-483, 2001.

18. Wolff AC, Hammond ME, Hicks DG, Dowsett M, McShane LM, Allison KH, Allred DC, Bartlett JM, Bilous M, Fitzgibbons P, et al: College of American Pathologists: Recommendations for human epidermal growth factor receptor 2 testing in breast cancer: American Society of Clinical Oncology/College of American Pathologists clinical practice guideline update. Arch Pathol Lab Med 138: 241-256, 2014.

19. Dawood S, Broglio K, Buzdar AU, Hortobagyi GN and Giordano SH: Prognosis of women with metastatic breast cancer by HER 2 status and trastuzumab treatment: An institutionalbased review. J Clin Oncol 28: 92-98, 2010.

20. Albain KS, Nag SM, Calderillo-Ruiz G, Jordaan JP, Llombart AC, Pluzanska A, Rolski J, Melemed AS, Reyes-Vidal JM, Sekhon JS, et al: Gemcitabine plus paclitaxel versus paclitaxel monotherapy in patients with metastatic breast cancer and prior anthracycline treatment. J Clin Oncol 26: 3950-3957, 2008.

21. Aogi K, Yoshida M, Sagara Y, Kamigaki S, Okazaki M, Funai J, Fujimoto T, Toi M, Saeki T and Takashima S: The efficacy and safety of gemcitabine plus paclitaxel combination first-line therapy for Japanese patients with metastatic breast cancer including triple-negative phenotype. Cancer Chemother Pharmacol 67: 1007-1015, 2011.

22. Takahara A, Koido S, Ito M, Nagasaki E, Sagawa Y, Iwamoto T, Komita H, Ochi T, Fujiwara H, Yasukawa M, et al: Gemcitabine enhances Wilms' tumor gene WT1 expression and sensitizes human pancreatic cancer cells with WT1-specific T-cell-mediated antitumor immune response. Cancer Immunol Immunother 60: 1289-1297, 2011.

23. Hernández-Vargas H, Rodríguez-Pinilla SM, Julián-Tendero M, Sánchez-Rovira P, Cuevas C, Antón A, Ríos MJ, Palacios J and Moreno-Bueno G: Gene expression profiling of breast cancer cells in response to gemcitabine: NF-kappaB pathway activation as a potential mechanism of resistance. Breast Cancer Res Treat 102: 157-172, 2007.

24. Cao Y, Luo JL and Karin M: IkappaB kinase alpha kinase activity is required for self-renewal of ErbB2/Her2-transformed mammary tumor-initiating cells. Proc Natl Acad Sci USA 104: 15852-15857, 2007.

25. Cao N, Li S, Wang Z, Ahmed KM, Degnan ME, Fan M, Dynlacht JR and Li JJ: NF-kappaB-mediated HER2 overexpression in radiation-adaptive resistance. Radiat Res 171: 9-21, 2009.

26. Tzahar E, Waterman H, Chen X, Levkowitz G, Karunagaran D, Lavi S, Ratzkin BJ and Yarden Y: A hierarchical network of interreceptor interactions determines signal transduction by Neu differentiation factor/neuregulin and epidermal growth factor. Mol Cell Biol 16: 5276-5287, 1996.

27. Spector NL and Blackwell KL: Understanding the mechanisms behind trastuzumab therapy for human epidermal growth factor receptor 2-positive breast cancer. J Clin Oncol 27: 5838-5847, 2009.

28. O'Brien NA, Browne BC, Chow L, Wang Y, Ginther C, Arboleda J, Duffy MJ, Crown J, O'Donovan N and Slamon DJ: Activated phosphoinositide 3-kinase/AKT signaling confers resistance to trastuzumab but not lapatinib. Mol Cancer Ther 9: 1489-1502, 2010.

29. Cancer Genome Atlas Network: Comprehensive molecular portraits of human breast tumours. Nature 490: 61-70, 2012

30. Yoshida R, Tazawa H, Hashimoto Y, Yano S, Onishi T, Sasaki T, Shirakawa Y, Kishimoto H, Uno F, Nishizaki M, et al: Mechanism of resistance to trastuzumab and molecular sensitization via ADCC activation by exogenous expression of HER2-extracellular domain in human cancer cells. Cancer Immunol Immunother 61: 1905-1916, 2012.

31. Scaltriti M, Verma C, Guzman M, Jimenez J, Parra JL, Pedersen K, Smith DJ, Landolfi S, Ramon y Cajal S, Arribas J, et al: Lapatinib, a HER2 tyrosine kinase inhibitor, induces stabilization and accumulation of HER2 and potentiates trastuzumab-dependent cell cytotoxicity. Oncogene 28: 803-814, 2009. 